\title{
Complete denture rehabilitation of edentulous patient with severe alveolar bone resorption using mandibular suction denture with closed mouth technique: a clinical report
}

\author{
Chang Woo Ko', Byungkwee Min', Hong-so Yang', Hyun-Pil Lim', Kwidug Yun, Jin-Ho Shin²* \\ 'Department of Prosthodontics, School of Dentistry, Chonnam National University, Gwangju, Republic of Korea \\ ${ }^{2}$ Design Dental Clinic, Gwangju, Republic of Korea
}

When it comes to treat patient with loss of vestibule, conventional denture impression have limitation which can cause problems of excessive border extension. Suction denture with closed mouth technique which was introduced to solve this problem, forms negative pressure being sealed denture flanges by mobile mucosa when the patient swallows and chews. Also, it can decrease patient's visiting time by taking impression and gothic arch tracing at once. In this case, considering patient's chief complain which is a loose fit of present lower denture, suction dentures with closed mouth technique was planned. (J Dent Rehabil Appl Sci 2018;34(1):56-62)

Key words: closed mouth technique; complete denture

\section{서론}

최근 임플란트의 등장으로 인해 과거 보철적으로 한계 가 있던 문제들에 대해 많은 해결책을 제시하고 있으나, 경제적 문제 혹은 심리적, 전신적 문제로 인해 임플란트 시술을 시행할 수 없는 경우도 여전히 많다. 총의치는 이 러한 점에서 무치악 환자에게 기능적, 심미적 요구 충족 시킬 수 있는 수복방법으로, 간단하고 경제적인 치료 방 법이다. ${ }^{1}$ 무치악 환자에서 총의치 치료는 상악의 경우, 의 치 지지 면적이 넓어 교합력에 저항할 수 있으며, 혀가 존 재하지 않아 음압을 통한 유지력 획득이 용이하다. 그러 나 하악의 경우 혀의 존재 등 해부학적인 한계로 인해 낮 은 유지력 및 평균 의치 지지 면적이 적어 교합력에 저항 할 수 있는 능력이 적다. 특히, 이미 지속적인 골 흡수가 진행되어 치조골이 적고 구강저가 낮을 경우 총의치 치

*Correspondence to: Jin-Ho Shin

Design Dental Cilinic, 47 Gwangbongmaeul-gil, Nam-gu, Gwangju, Republic of Korea

Tel: +82-62-671-2800, Fax: +82-62-530-5639, E-mail: ddcsjh@gmail.com

Received: September 22, 2017/Last Revision: October 18/Accepted: October 25, 2017
료 시 만족스러운 결과를 얻기 쉽지 않다. ${ }^{2}$

인상 채득은 의치 지지조직을 이루는 구강조직의 음형 의 채득으로서, 구강조직의 단순한 채득(impression taking)이라기 보다는 술자의 의도에 의해 적절히 만들어지 는 조직의 채득(impression making)이다. 유지력을 증가 시키기 위해 인상 채득 시, 의치와 조직과의 긴밀한 적합 을 얻는 기존의 총의치 제작 방법은 정확한 변연 형성을 얻는 과정에서 술자의 기술과 경험에 의존적이다. ${ }^{3}$

폐구인상법을 이용한 총의치는 의치상연 주변을 가동 점막으로 봉쇄하여, 연하나 교합 시 의치 내면에서 일시 적으로 음압이 형성되도록 하는 방식으로 의치의 유지와 안정을 강화한다. 이는 인상 채득 시, 술자의 손가락에 의 해 발생 가능한 장애 없이 변연 형성이 가능하여, 술자에 따라 결과의 차이가 크지 않다. 또한, 인상채득과 함께 악간 관계를 동시에 얻을 수 있어 통상적인 방법에 비해

Copyright@ 2018 The Korean Academy of Stomatognathic Function and Occlusion. (c) It is identical to Creative Commons Non-Commercial License. 
내원 횟수가 절약되는 장점이 있다. ${ }^{4}$

본 증례의 환자는 기존의 의치가 너무 헐렁거리고 자주 빠진다는 주소로 내원한 완전 무치악 환자로, 지속적인 치조골 소실로 인해 하악의 구강전정이 매우 얕아져 있 는 등 기존 의치의 유지력이 상실된 상태였다. 하악 의치 의 유지 및 안정을 높이기 위해 폐구인상법을 통한 총의 치로 수복한 증례이다.

\section{증례보고}

본 증례의 환자는 80 세 남성으로, 약 10 여년 전 제작한 상, 하악 총의치의 적합성이 떨어지고 특히, 하악 총의치 가 헐거워 자주 빠진다는 주소로 내원하였다(Fig. 1). 전 신병력으로는 골다공증으로 약 1년여간 약물 복용 중이 었으며, 청각장애 4급 판정을 받은 환자로 어음 분별력이 상당히 떨어져 있었다. 진단을 위하여 파노라마 방사선 사진 촬영 및 진단 모형을 위한 인상 채득을 시행하였다 (Fig. 2). 상하악 모두 약 10 여년 전 제작한 총의치를 사용 하고 있었으나, 최초 제작 이후 치과에서 정기검진을 받 지 않고 그대로 사용한 나머지 유지력과 적합성 모두 부 족한 상태였다. 환자의 경제적인 상황과 골다공증 및 환
자 본인의 거부감으로 인해 임플란트 식립 및 전정성형술 등의 외과적 술식을 배제한 상하악 총의치를 제작하기로 하였다. 지속적인 치조골 흡수로 인해 구강전정이 얕은 환자임을 고려하여 폐구법을 이용한 총의치를 통해 유지 력 및 적합성 향상을 도모하기로 하였다.

최초 내원 시, 개인트레이 제작을 위한 인상채득과 함 께, Centric Tray ${ }^{\circledR}$ (Ivoclar Vivadent AG, Schaan, Liechtenstein)를 이용하여 대략적인 교합관계를 채득하였다 (Fig. 3). 이 후 이를 바탕으로 진단 모형을 Horizontal Guide $^{\circledR}$ (Ivoclar Vivadent AG)를 이용하여 교합기 Stra-

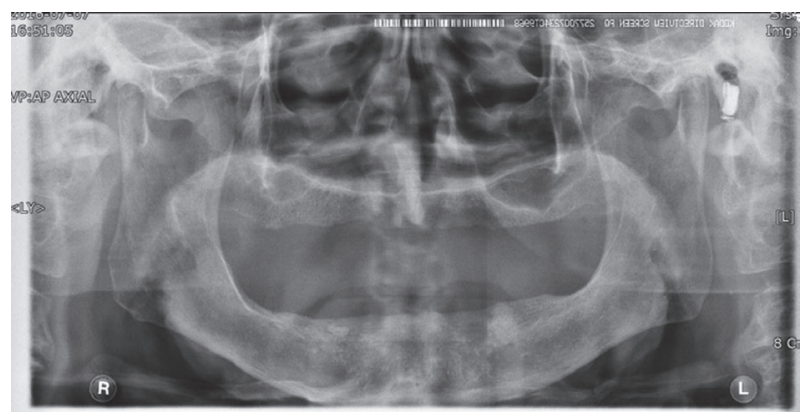

Fig. 2. Panoramic view at initial visit.
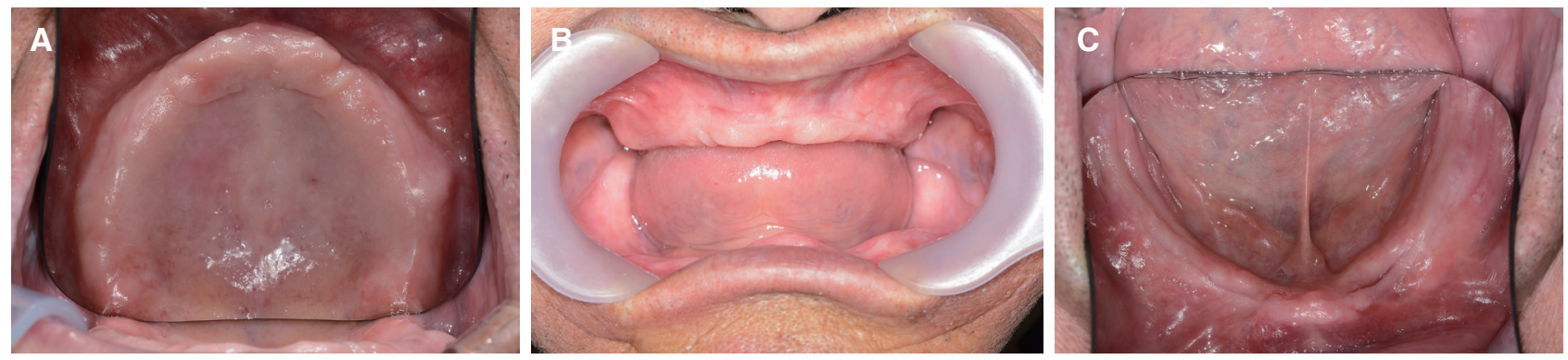

Fig. 1. Intraoral photo image at initial visit. (A) Maxillary occlusal view, (B) Frontal view, (C) Mandibular occlusal view.
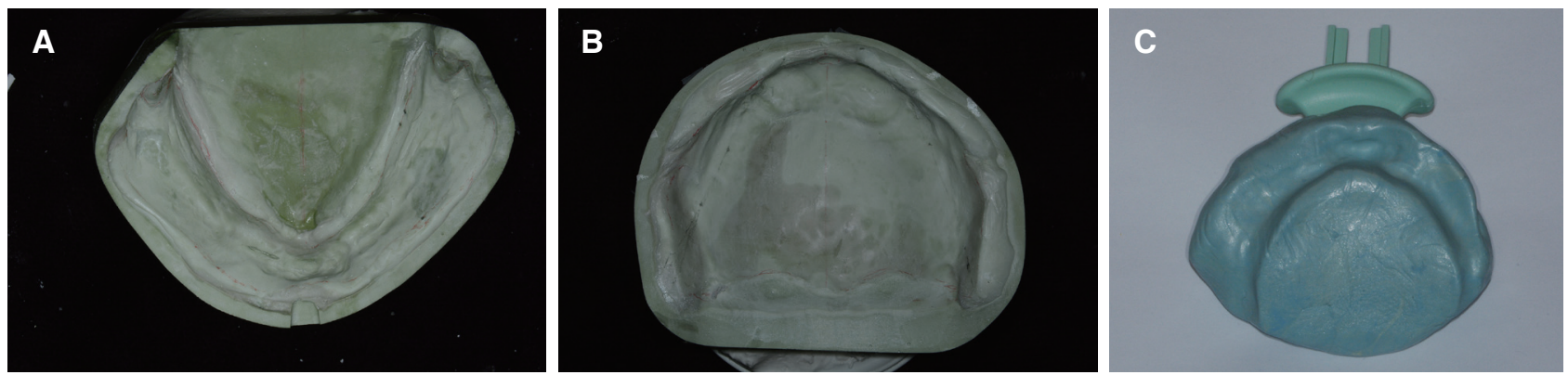

Fig. 3. Preliminary impression. (A) Upper jaw, (B) Lower jaw, (C) Bite taking with Centric Tray ${ }^{\circledR}$ (Ivoclar Vivadent AG, Schaan, Liechtenstein). 
tos $300^{\circledR}$ (Ivoclar Vivadent AG) 에 부착하였다(Fig. 4). 이 후 환자의 상하악 모형의 해부학적 요소들을 고려하 여 최대한 흡착 봉쇄 매커니즘을 달성하도록 의치상이 과연장되지 않게 제작하였다. 설계 시, 후구치 삼각 융기 부위를 포합하여 후악설골근와부로 $2 \mathrm{~mm}$ 가량 연장하 였으며, 협측으로는 골외사선 부위가 아닌, 치은협이행부 최하점을 기준으로 하였다. 개인트레이를 제작하고, 1 차 적으로 교합기에 부착된 진단모형을 통해 대략적인 환자 의 악간관계에 맞추어 Gnathometer $\mathrm{M}^{\circledR}$ (Ivoclar Vivadent AG)를 위치시켰다(Fig. 5).

다음 환자 내원 시, 미리 제작한 개인 트레이를 이용하 여 폐구법으로 인상채득을 하였다. 먼저 heavy body의 polyvinylsiloxane 인상재(Honigum Heavy body, DMG, Hamburg, Germany)로 변연 형성을 한 뒤, 흐름성이 뛰 어난 light body의 polyvinylsiloxane 인상재(Honigum Light body, DMG)를 이용하여 가급적 무가압 인상에 가
깝게 채득되도록 하였다. 이 때 환자로 하여금 입을 다문 상태에서 근육의 기능 운동을 시키며 변연형성 및 최종인 상을 채득하였다. 환자로 하여금 술자의 손가락을 빨도 록 하거나 ‘잇’, ‘웃' 하는 발음을 이용하여 구강 주변 근육 들의 움직임이 기록되도록 하고 개구 상태에서 혀를 좌우 로 움직이게 하여 혀의 운동이 채득되도록 한 후, 폐구 상 태에서 혀의 운동이 기록되도록 트레이 안쪽을 밀도록 한 뒤 연하 운동을 시켰다(Fig. 6).

최종 인상 채득 후 환자에게 소리 내어 숫자를 거꾸로 세도록 하며 Gnathometer $\mathrm{M}^{\circledR}$ (Ivoclar Vivadent AG)의 간격을 늘리면서 적절한 발음공간을 확인하여 교합고경 을 설정하였다. 이 후, 환자 스스로 무리 없이 가볍게 후 방에서 교합하도록 지시하며 묘기법(Gothic arch tracing)을 시행하여 최종적으로 중심위를 결정하였다(Fig. 6). 안궁이전 시행 후, 채득된 최종 인상체로부터 DS Ratio stone ${ }^{\circledR}$ (Odic denture, Osaka, Japan)을 이용하여 주
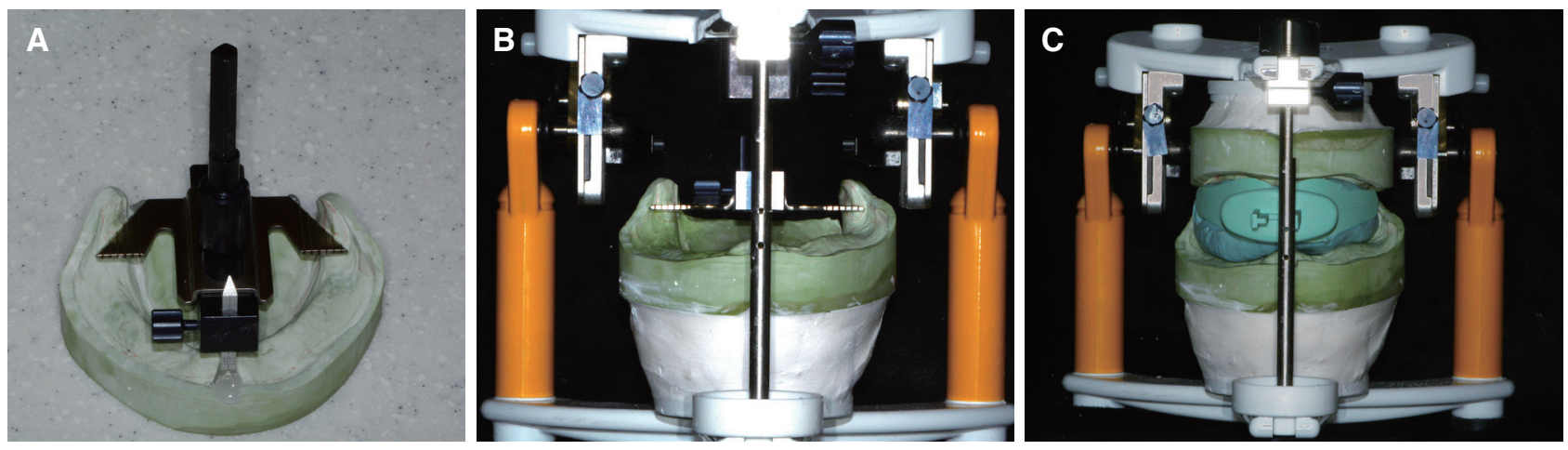

Fig. 4. (A) Horizontal Guide ${ }^{\circledR}$ (Ivoclar Vivadent AG, Schaan, Liechtenstein), (B) Lower cast mounting with Horizontal guide on Stratos $300^{\circledR}$ (Ivoclar Vivadent AG), (C) Upper jaw mounting with Centric tray ${ }^{\circledR}$ (Ivoclar Vivadent AG). Using Horizontal Guide ${ }^{\circledR}$ and bite taken with Centric Tray ${ }^{\circledR}$ at initial visit, upper and lower diagnostic casts can be approximately mounted on Stratoss $300^{\circledR}$.
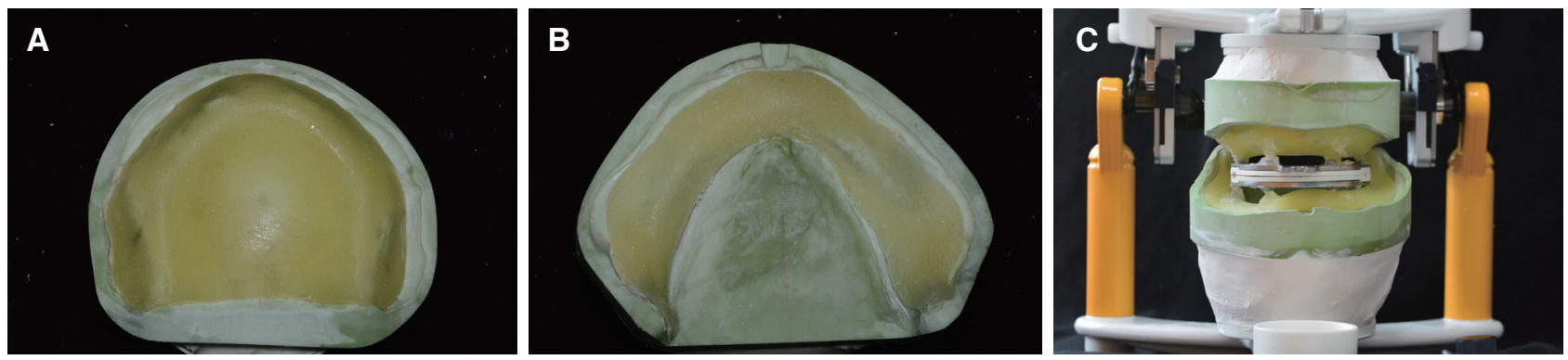

Fig. 5. Individual tray fabrication. (A) Upper jaw, (B) Lower jaw, (C) Gnathometer $\mathrm{M}^{\circledR}$ (Ivoclar Vivadent AG, Schaan, Liechtenstein) placement. After fabrication of individual trays, Gnathometer M was installed at retromolar pad 1/2 level. 

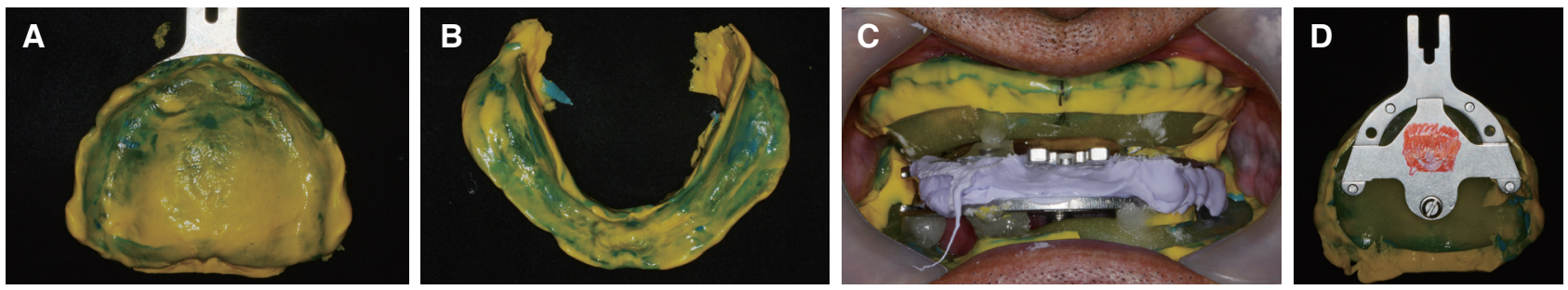

Fig. 6. Final impression. (A) Upper jaw, (B) Lower jaw, (C) Closed mouth technique with Gothic arch tracing, (D) Gothic arch tracing.
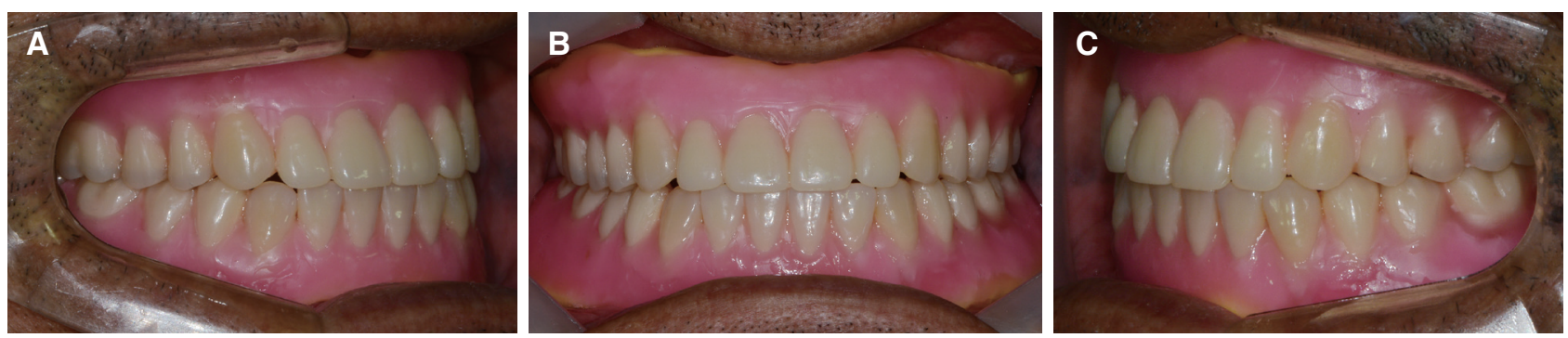

Fig. 7. Wax denture try-in. (A) Right lateral view, (B) Frontal view, (C) Left lateral view. Wax denture try-in process is necessary to check lip supports when using Gnathometer $\mathrm{M}^{\circledast}$ for closed mouth technique instead of occlusal rim.
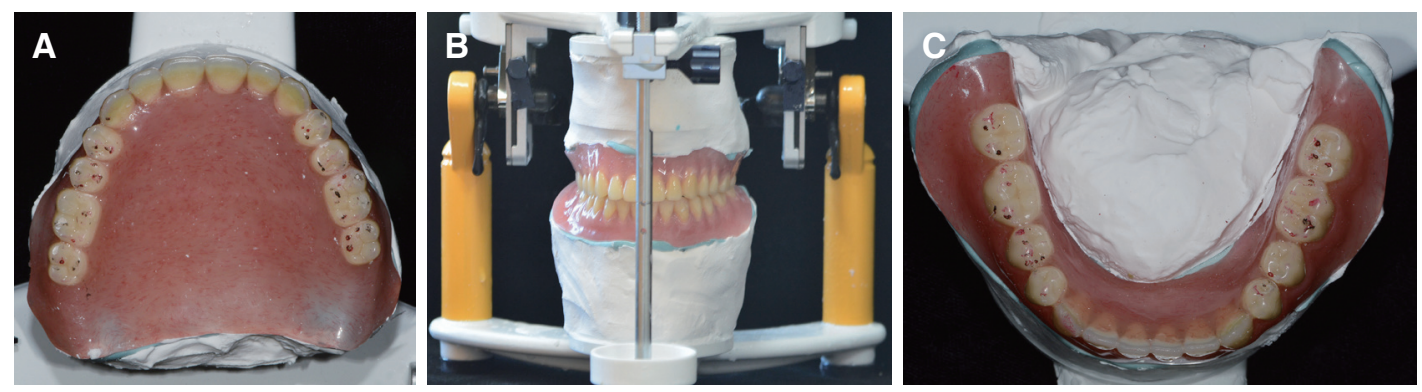

Fig. 8. Clinical remounting. (A) Maxillary occlusal view, (B) Clinical mounting, (C) Mandibular occlusal view.
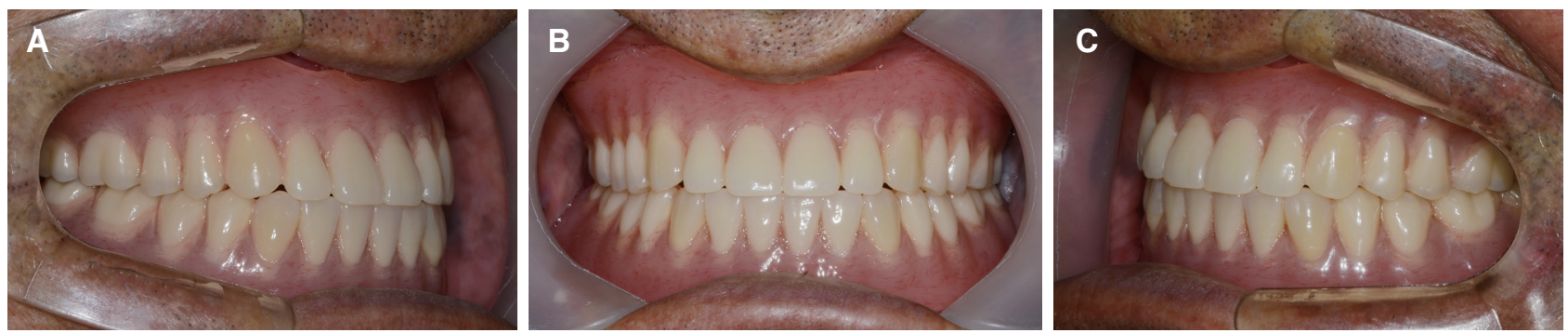

Fig .9. Definitive prosthesis delivery. (A) Right lateral view, (B) Frontal view, (C) Left lateral view.

모형을 제작하였다.

치아 배열 후 납의치 상태에서 환자 구강 내 시적 후 구 순지지 정도와 구음이나 연하 시 연마면 형태가 변연 봉 쇄에 적합한지 확인하였다(Fig. 7). 최종 의치 제작 시, DS resin ${ }^{\circledR}$ (Odic denture)을 이용하여 온성 후 기공실 재
부착을 통해 오차를 수정하였다. 이 후 환자 구강 내에서 시적 후 진료실 재부착 과정을 거친 후 환자에게 의치를 장착하였다(Fig. 8, 9). 치료 이 후 2개월 간의 임상관찰 결과, 구강 내에서 의치는 안정적인 유지를 보였으며, 환 자도 심미적, 기능적으로 만족하였다. 


\section{고찰}

폐구인상법을 이용한 의치는 의치상연 주위 전체를 가 동 점막으로 봉쇄하여 연하나 교합 시 의치상 내면에 일시 적 음압이 형성되게 하여 의치의 유지와 안정을 높이도록 고안된 의치이다. 인상 채득 시, 내압 면적을 확대하여 의 치를 최대한 악골에 밀착시킴으로써, 의치의 유지와 안정 을 얻는 기존의 총의치 제작 방법은 술자의 기술과 경험에 따라 그 결과가 크게 달라진다. 이에 반하여 Abe 등 ${ }^{4}$ 이 소 개한 폐구인상법을 이용한 의치는 환자 본연의 기능 운 동을 토대로 인상채득이 이루어지므로, 술자에 따른 결 과의 차이가 크지 않다. ${ }^{4}$

본 증례의 환자는 골다공증 및 환자의 거부감을 이유로 임플란트 식립이 어려운 점을 고려하여, 기존 의치의 유지 력이 감소되어 불편하다는 주소를 해결하기 위해 더 나은 유지력을 얻어내도록 폐구인상법을 통한 흡착식 의치를 제작하기로 결정하였다. 폐구인상법은 환자 본인의 기능 운동을 통해 변연 형성이 이루어지기 때문에, 환자가 실제 의치를 착용하고 기능하는 동안 더 좋은 안정과 유지를 얻을 수 있다. 또한 인상 채득과 악간관계 기록이 동시에 이루어져 기존의 방법보다, 내원 횟수를 감소시킬 수 있다 는 장점이 있었으며, 환자 본인의 재현성있는 운동을 기반 으로 채득되기 때문에 술자의 경험과 숙련도에 관계 없이, 비교적 일정한 결과를 나타낸다는 장점이 있다.

이러한 폐구인상법을 통한 의치가 높은 유지력을 갖기 위해서는 의치상과 치조제의 긴밀한 접촉과 동시에, 주 위 가동 점막을 통한 봉쇄가 일어나야 한다. 특히, 후구 치 융기부위에서 의치의 연마면과 혀와 협점막이 만나는 buccal mucosa tongue contact (BTC) point의 형성이 필 수적이다. ${ }^{4}$ 이는 인상채득 시 개인트레이의 후구치 융기 부위에서 BTC point가 형성된 것을 통해 확인할 수 있다 (Fig. 10). 이를 위해서는 개인트레이 설계 시, 협붕 부위 를 과도하게 포함하지 않도록 하는 것이 중요하다. 협붕 부위가 과도하게 포함될 시에는 BTC point 형성이 잘 이 루어 지지 않을 수 있다.

폐구인상법은 술자가 의도한 대로 압력을 조절할 수 없다는 단점이 있어, 최대한 무가압인상을 채득하여야 한다. 이를 위해, 변연 형성 시를 제외하고, 최종 인상 시 에는 가급적 흐름성이 높은 인상재를 이용하여 인상채 득을 시행하였다. 또한, 청각장애 4 급인 환자였기에 폐 구인상으로 채득 시, 사전에 충분히 의사소통하며 발음 시험 및 기능운동을 연습한 후에 시행하였다. 이 증례에

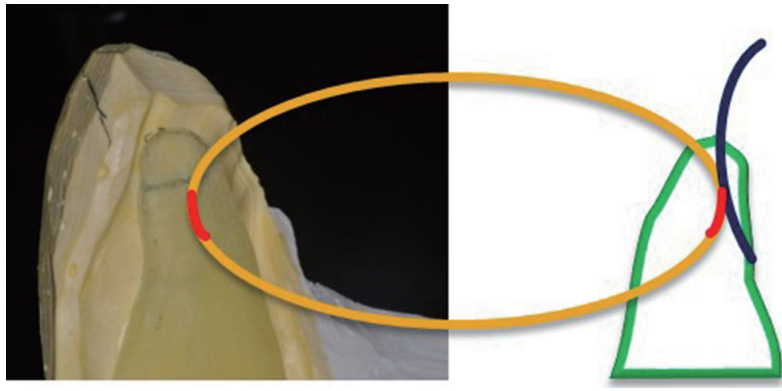

Fig. 10. BTC (Buccal mucosa and Tongue Contact) point. Posterior border seal above the retromolar pad when closing mouth. When patient close mouth, buccal mucosa and tongue side wall contact each other above retromolar pad area of denture which reinforce posterior border seal.

서는 교합제를 이용하지 않고 Gnathometer $\mathrm{M}^{\circledR}$ (Ivoclar Vivadent AG)를 이용하여 폐구인상을 진행하였기에 납 의치 시적 단계에서 구순지지에 대한 확인이 필수적이었 다.

또한 재료적인 측면에서 의치의 중합 및 온성 과정에 서 모형과 레진에 열이 가해짐으로 인한 수축 및 오차를 최소한으로 줄이는 것이 의치의 유지력 향상에 더욱 도 움이 된다. 이를 위하여, 가급적 수축률 및 오차가 최소 화되도록 고안된 DS Ratio stone ${ }^{\circledR}$ (Odic denture) 및 DS $\operatorname{resin}^{\circledR}$ (Odic denture)을 이용하여 각각 모형과 의치를 제 작한 결과, 실제로 기공실 재부착 및 진료실 재부착 과정 에서 수정해야 할 교합 오차의 양이 거의 없었으며, 환자 의 구강 내에서 의치상의 적합도도 뛰어남을 확인할 수 있었다.

통상적인 방법으로의 개인 트레이는 의치의 내압 면적 을 가능한 넓게 획득 하여 저작 시의 의치의 안정을 얻도 록 제작 되지만, 폐구인상법을 이용한 의치는 하악 의치 의 흡착을 달성하기 위하여 후구치 삼각융기 부위를 포 함하는 후방영역의 개인 트레이 설계선이 중요하다. 이 를 위하여 개인 트레이 제작을 위한 예비 인상 채득 시, 근육의 부착부위가 선명하게 나타나도록 압력이 가해지 기 보다는, 후구치 삼각융기 부위를 가능한 한 변형시키 지 않으면서 자연스러운 구강 내의 형태를 채득하는 것 이 중요하다. 


\section{결론}

본 환자는 잔존치조골의 흡수로 인해 구강전정이 얕아 져 기존 의치의 유지 및 안정성이 부족하였던 환자로, 통 상적인 방법이 아닌 폐구인상을 통한 총의치를 제작하여 내원 횟수를 줄임과 동시에 만족스러운 유지 및 안정성 을 보였다.

\section{ORCID}

Chang Woo Ko https://orcid.org/0000-0002-1973-5627

Byung-Kwee Min https://orcid.org/ 0000-0003-27562284

Hong-So Yang https://orcid.org/0000-0002-9138-4817

Hyun-Pil Lim https://orcid.org/0000-0001-5586-1404

Kwi-Dug Yun https://orcid.org/0000-0002-2965-3967

Jin-Ho Shin https://orcid.org/0000-0003-2072-0614

\section{References}

1. Douglass CW, Shih A, Ostry L. Will there be a need for complete dentures in the United States in 2020? J Prosthet Dent 2002;87:5-8.

2. Tallgren A. The continuing reduction of the residual alveolar ridges in complete denture wearers: a mixed-longitudinal study covering 25 years. J Prosthet Dent 2003;89:427-35.

3. Collett HA. Final impressions for complete dentures. J Prosthet Dent 1970;23:250-64.

4. Abe J. Difference of preliminary impression takings between conventional mandibular complete denture and the mandibular complete denture intended with effective suction. Pract Prosthodont 2010;43: 510-24. 


\section{치조골 흡수가 심한 완전 무치악 환자에서 폐구인상법을 이용한 총의치 수복 증례}

\section{고창우 ${ }^{1}$, 민병귀 ${ }^{1}$, 양홍서 ${ }^{1}$, 임현필 ${ }^{1}$, 윤귀덕 ${ }^{1}$, 신진호*}

${ }^{1}$ 전남대학교 치의학전문대학원 치과보철학교실

${ }^{2}$ 디자인치과의원

총의치 제작을 위한 개구인상법은 술자의 숙련도에 따라 다르게 나타나며, 특히 구강전정이 얕은 환자에서는 변연이 과 연장되어 채득되는 문제가 발생할 수 있다. 이러한 문제를 해결하기 위해 제안된 폐구인상법을 통한 총의치는 연하나 교 합 시 의치상연 주위 전체를 가동 점막으로 봉쇄하여 의치상 내면에 일시적 음압이 형성되게 하여 의치의 유지와 안정을 높이도록 고안된 의치이다. 또한, 인상 채득 시 교합채득 및 묘기판을 이용한다면 악간관계 기록이 동시에 이루어지기 때 문에 기존의 통상적인 방법보다 환자의 내원 횟수를 줄일 수 있다. 이 증례는 구강전정이 얕아 하악 의치의 유지력이 떨 어져 불편을 겪는 환자에서, 폐구인상법을 이용한 총의치로 수복한 증례이다.

(구강회복응용과학지 2018;34(1):56-62)

주요어: 폐구인상법; 총의치 